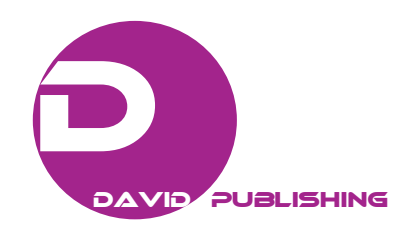

\title{
Analysis of Evacuation Efficiency with Congestion Points in Large Sport Facilities
}

\author{
Chen-Wei Chiu ${ }^{1}, \mathrm{Yu}-\mathrm{Hsiu} \mathrm{Li}^{1}$, Yi-Liang $\mathrm{Shu}^{2}$ and Chi-Min Shu ${ }^{3}$ \\ 1. Department of Fire Safety, National Taiwan Police College, Taipei 11696, Taiwan, Republic of China \\ 2. Department of Safety Health and Environmental Engineering, Central Taiwan University of Sciences and Technology, Taichung \\ 40601, Taiwan, Republic of China \\ 3. Department of Safety, Health, and Environmental Engineering, National Yunlin University of Science and Technology, Yunlin \\ 64002, Taiwan, Republic of China
}

\begin{abstract}
Large leisure activities usually use large sport facilities. There is often no serious problem with people gathering, but both incomplete facilities and negligence of people security manage may court injury or death. The purpose of this study is to analyze crowded nodes and to improve evacuation path use Simulex models. The fastest and safest way to achieve safe egress was then well planned. For turn locations, it was found that fixing the plane angle did not significantly raise the overall exiting efficiency. However, replacing the right angle or other angles with arc angle makes overall exiting moving line more fluent. For multi- to single-directional converging T-junction intersections, modification of turn angle increased the movement fluency, with the higher the modified angle, the higher in fluency. However, changing to round angle did not have as significant effect as expected while gate opening width must be increased to $1.0 \mathrm{~m}$ before more significant effects were produced. The results showed that modifying turn angles to $60^{\circ}$ produces better improvements.
\end{abstract}

Key words: Large activity, large sport facilities, Simulex, security manage, evacuation path, safe egress.

\section{Introduction}

A large sports facility is defined as a dome, arena, gymnasium, or stadium designed to host large-scale spectator activities, such as sporting events, rallies, art shows, exhibitions, concerts, or musicals that can accommodate more than 5,000 people and that is distinct from general purpose fitness clubs and integrated gymnasiums that simply serve as sites for sports activities.

Because of the high usage rates and large-scale nature of sports facilities, poor evacuation planning can lead to the risk of disasters and high casualty crises. Therefore, evacuation planning and safety control measures are important issues of concern for large sports facilities.

Corresponding author: Chen-Wei Chiu, Ph.D., associate professor, research field: fire protection engineering. E-mail: eswin.wei@gmail.com.
Large sport facilities or stadiums and public access areas are now commonly found in large-scale development projects [1]. These public areas are always crowded with people during holidays and/or weekends. The occupancy levels (or occupant loadings) are observed to be much higher than the design values. Evacuation design is considered to be the key item and depends on the occupant loading under crowded conditions. The prescriptive codes [2], on both passive construction elements and active fire engineering systems, might not provide adequate protection for those big crowded public areas. It has been suggested that the movement speed of the occupants vary according to the travel types, occupant's density, occupant characteristics, and travel conditions [3-6].

Evacuation simulation models can be used to predict the performance of evacuations in a specific building and thus become an important tool for performing the building evacuation analysis. The present simulation 
models can be divided into two categories: fine and coarse networks. In the fine network approaches, such as EXITT, EGRESS, MAGNETMODEL, BGRAF, EXODUS, SUMULEX, and VEGAU [7-12], Thompson and Marchant [12] used the Simulex evacuation simulation software to simulate the escape action of large groups of people in order to test the design of these geometrically complex building spaces, and suggested that the software model be suitable for use as a research and design tool to analyze how large numbers of people vacate building premises. The second category of model not only takes into account the physical characteristics of the enclosure but treats the individual as an active agent taking into consideration his or her response to stimuli such various tier hazards and individual behaviors, such as personal reaction times and exit preference. An example of this type of model is to build EXODUS [13, 14].

There have been considerable studies on controlled evacuation experiments to gain data in different locations, such as high-rise apartments, large retail stores, ships, classrooms, and public transport terminals [15-18]. Data on disabled occupants have also been collected in other experiments [19]. Hoogendoorn and Daamen [20] studied actual pedestrian moving characteristics when crossing bottlenecks, and Hoogendoorn and Bovy [21] found the emergence of self-organized pattern in vertical groups of moving pedestrians. Kretz et al. [22] studied pedestrian counterflow in a corridor by investigating the flow characteristics of pedestrian, including the speed-density relation, fundamental diagram as well as lane formation.

The purpose of the present study was to analyze nodes of crowding using computer simulations in order to come up with an improved method of identifying the best evacuation path for the subjects in the study, and then to use the method to improve plans for moving people in the fastest and most secure way possibly within the shortest period of time.

\section{Simulex and Analysis Congestion Points in Building}

\subsection{Simulex}

Simulex [23] is an evacuation simulation software program developed by Integrated Environmental Solutions Ltd. of Great Britain that uses computer-aided designed floor plans with stairway and exit links to create floor level simulations of building interior escape situations. Simulex can simulate the evacuation of wide open areas or complex compartmentalized buildings. Based on the results from the amount of time and the path taken to evacuate people, it is possible to appraise the appropriateness of evacuation facilities and safety measures of these buildings in terms of evacuation guidance facilities and escape route planning. They can also help to review existing laws and evacuation facility requirements, such as the number and configuration of stairs and width restrictions on exits and staircases. A person's tendency toward taking evacuation and the ability to act quickly will affect the evacuation situation. Evacuation principles based on more than one direction and the concept of establishing a safe refuge area in the building to be used while waiting for the arrival of outside help can provide evacuees some breathing room.

In the evacuation simulation process, Simulex makes the following assumptions about the traveling speed of each person:

- Individual evacuee is in a normal state of psychological and physiological conditions with no obstacle to any forward movement speed;

- Traveling speed of a person is reduced when that person is encroached by another person;

- The direction of movement is determined by having the person facing front toward the exit during traveling;

- There will be some individuals who will pass others, turn around, move sideways, or slightly fall behind. 


\subsection{Case Selection}

The study chose the Big Taipei Dome's indoor multi-purpose sports hall, which can accommodate 40,000 seats that include approximately 30,000 infield seats and 10,000 outfield seats and has a height of about $65 \mathrm{~m}$ which is designed for multi-purpose gatherings such as large scale games, rallies, performances, and exhibitions. Fig. 1 shows the first floor plan.

\subsection{Common Congestion Points in Buildings}

Previous literature and observation of people movement made in this study showed the following few common congestion points.

\subsubsection{Gate Crossing}

Gate crossing along the moving line, often due to the need to control people going in and out, is designed with relatively narrow width and few in number. The speed of people moving through it slows down greatly, resulting in traffic congestion.

\subsubsection{Stair Exits}

Stairs along the moving line are limited by the width and number of stairs available. When a large number of crowds reach a stair point, a sudden speed reduction to accommodate for the need to make the pass separately could cause congestion on the stairs.

\subsubsection{Around a Turn}

The moment when a crowd encounters a turn along the moving line, the change in traveling direction causes the traveling speed to slow down. Since if the traveling speed of the crowd approaching a turn does not change, it will cause congestion at that turn location (shown in Fig. 2) due to slowing down of people in front.

2.3.4 Multi-directional Convergence into a Single Direction

When people from all directions are converging into a single direction all at once, the passageway can no longer quickly absorb so many people, causing converging point to congest from slow-moving crowd (as shown in Fig. 3).

\subsubsection{Intersection of Different Directions}

Since people move in different directions along the moving line, mutual dodging or comity can cause movement stoppage or slowdown, forming intersection congestion.

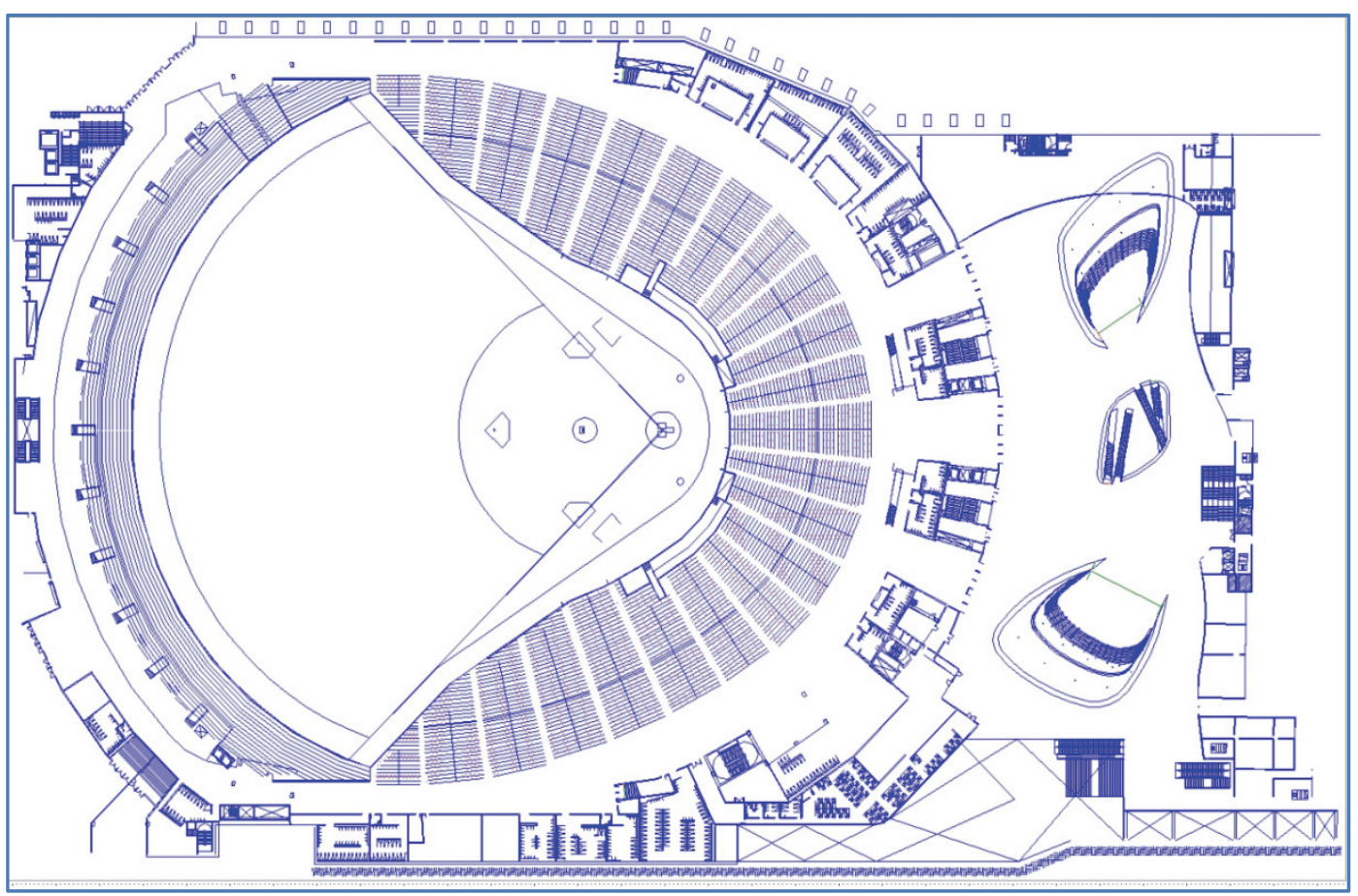

Fig. 1 The first-floor plan. 


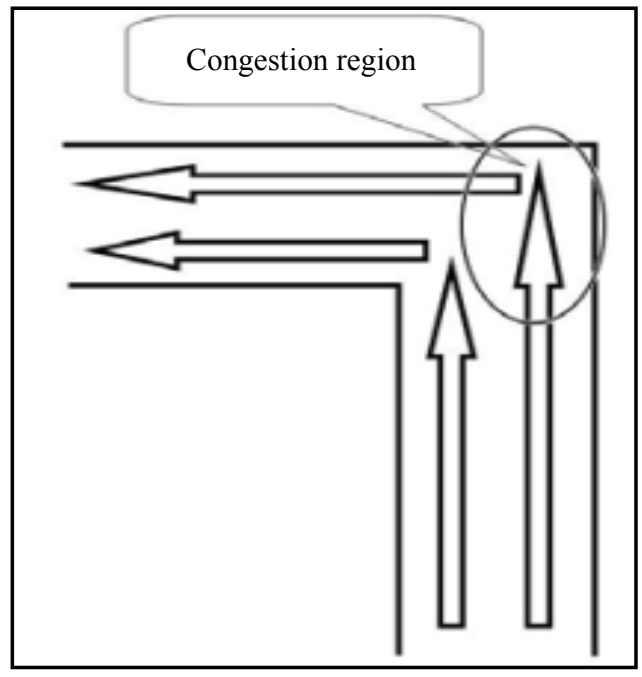

Fig. 2 Congestion point diagram at a turn location [24].

The engineering or management improvement plans for these common congestion points are listed in Table 1.

\section{Analysis of Improvements on Congestion Point}

\subsection{Description of Scenarios}

The possible congestion alleviating solutions found against frequently seen congestion points mentioned in Section 2.3 were used to design the following scenarios to improve the efficiency of the exiting process, as explained in Table 2.

\subsubsection{Scenario 1 (Gate Crossing)}

This scenario is for simulating improving congestions at the gate crossing: Scenario 1-1 is the original setup (five crossing gates width of $50 \mathrm{~cm}$ each), where the width is designed using standard width dimension adopted for the ticket gate of MRT (mass rapid transit) in Taipei; Scenario 1-2 is for increasing the number of crossing gates (seven crossing gates with width of $50 \mathrm{~cm}$ each); Scenario 1-3 increases the number of crossing gates (nine crossing gates with width of $50 \mathrm{~cm}$ each); Scenario 1-4 modifies the width of the crossing gates (five crossing gates with width modified to $70 \mathrm{~cm}$ each); Scenario 1-5 modifies the width of the crossing gates (five crossing gates with width modified to $100 \mathrm{~cm}$ each); Scenario 1-6 modifies the width of the crossing gates (five crossing gates with width modified to $150 \mathrm{~cm}$ each).

\subsubsection{Scenario 2 (Stair Exit)}

This scenario is for simulating improving congestions at stair locations: Scenario $2-1$ is the original setup (with only one regular stair with width of $2.4 \mathrm{~m}$ open) where the design for the width of regular

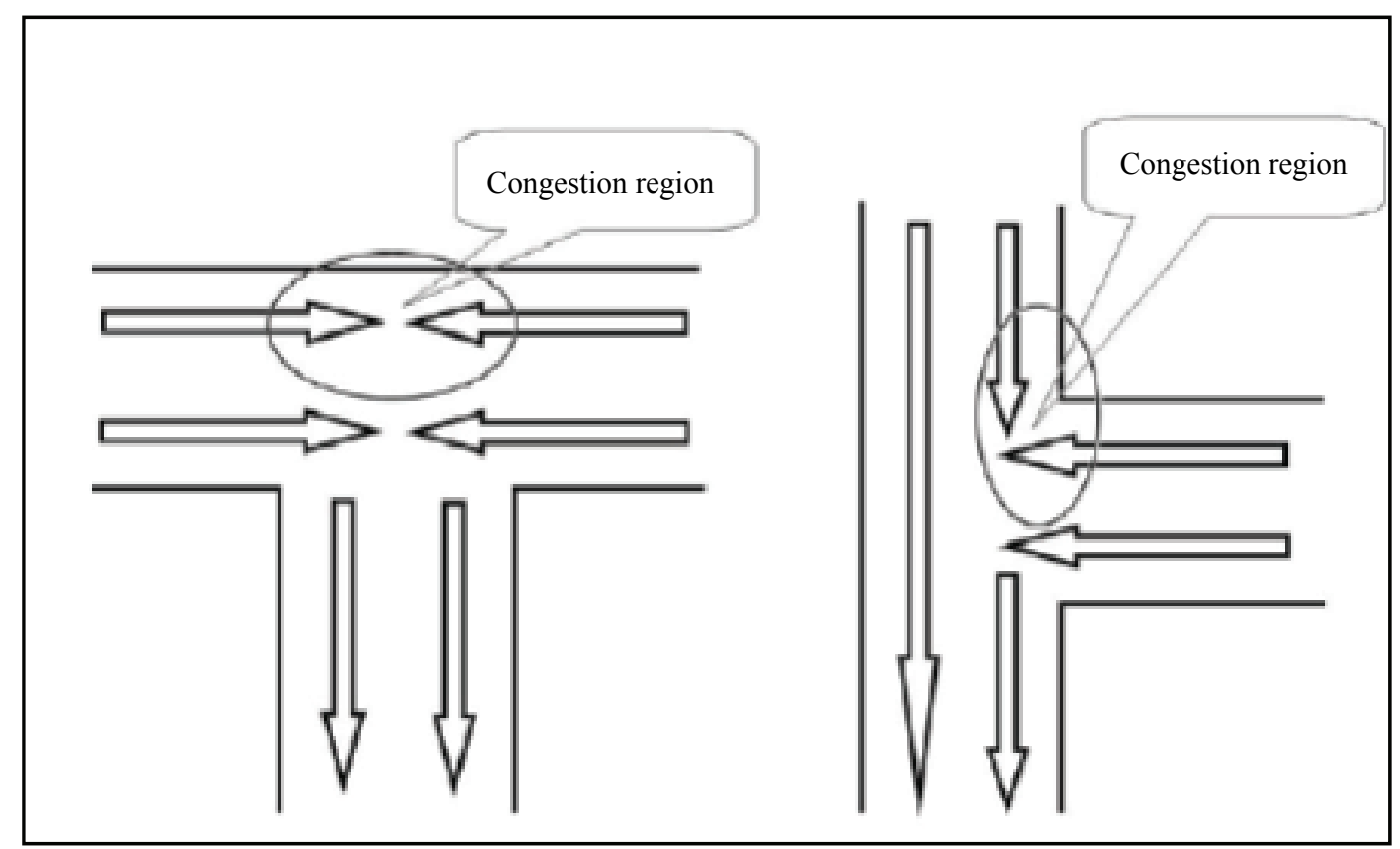

Fig. 3 Congestion point diagram of multi-directional convergence [24]. 
Table 1 Improvement analysis of building facilities at congestion points.

\begin{tabular}{|c|c|}
\hline Name & Solution \\
\hline Gate crossing & $\begin{array}{l}\text { Increase the number of crossing gates } \\
\text { Increase the width of crossing gates } \\
\text { Direct people to cross separately in smaller groups } \\
\text { Direct people to other crossing gates }\end{array}$ \\
\hline Stair location & $\begin{array}{l}\text { Increase the number of stairs } \\
\text { Direct people to cross separately in smaller groups } \\
\text { If necessary, set it to single direction to alleviate congestion }\end{array}$ \\
\hline Turn location & $\begin{array}{l}\text { Avoid forming a } 90^{\circ} \text { angle at turn locations } \\
\text { Change the angle of turn locations }\end{array}$ \\
\hline $\begin{array}{l}\text { Point of multi-directional convergence } \\
\text { into a single direction }\end{array}$ & $\begin{array}{l}\text { Avoid forming a T-junction at intersection } \\
\text { Change the entrance angle of the T-junction at intersection } \\
\text { Change the entrance width of T-junction at the intersection } \\
\text { Direct people to cross separately in smaller groups }\end{array}$ \\
\hline Intersection of different directions & $\begin{array}{l}\text { Mark the moving line of each direction and guide it toward the desired direction } \\
\text { Direct people to cross separately in smaller groups }\end{array}$ \\
\hline
\end{tabular}

Table 2 Description of scenarios.

\begin{tabular}{lll}
\hline Scenarios & Scenario name & Simulated scenario \\
\hline Scenario 1 & Gate crossing & $\begin{array}{l}\text { Original diagram unmodified } \\
\text { Increase number of crossing gates } \\
\text { Modify width of crossing gates }\end{array}$ \\
\hline Scenario 2 & Stair location & $\begin{array}{l}\text { Original diagram unmodified } \\
\text { Increase one escalator } \\
\text { Increase two escalators }\end{array}$ \\
\hline Scenario 3 & Turn location & $\begin{array}{l}\text { Original diagram unmodified } \\
\text { Modify turn angle }\end{array}$ \\
\hline \multirow{2}{*}{ Scenario 4} & Multi-directional convergent point & $\begin{array}{l}\text { Original diagram unmodified } \\
\text { Modify convergent point angle } \\
\text { Modify convergent point width }\end{array}$ \\
\hline
\end{tabular}

stairs and escalators uses the stair width standard adopted for Taipei MRT platform; Scenario 2-2 is for adding one escalator to simulate normal exiting process of people in a situation where there are only one regular stair and one escalator (with width of $2.4 \mathrm{~m}$ for the stair and $1.0 \mathrm{~m}$ for the escalator); Scenario 2-3 adds two more escalators to simulate single directional exiting process, similar to New Year's Eve celebration (with width of $2.4 \mathrm{~m}$ for the steps of the regular stairs and $1.0 \mathrm{~m}$ for the escalators).

\subsubsection{Scenario 3 (Turn Location)}

This scenario is for simulating improving congestions at the turns: Scenario 3-1 is the original setup (with two $90^{\circ}$ turns) that simulates congestion of people walking pass through the turn; Scenario 3-2 modifies the $90^{\circ}$ turn into another angle ( $45^{\circ}$ turn); Scenario 3-3 modifies the $90^{\circ}$ turn into another angle ( $60^{\circ}$ turn); Scenario 3-4 modifies the $90^{\circ}$ turn into a rounded turn.
3.1.4 Scenario 4 (Multi-directional Convergent Point)

This scenario is for simulating improving congestion when traffic approaches from multi-directions: Scenario 4-1 is the original setup that uses T-junction cross street to simulate congestion when people converge from various directions; Scenario 4-2 is when the T-junction's $90^{\circ}$ entrance turn angle $2 \mathrm{~m}$ into the entrance location is beveled to $30^{\circ}$; Scenario 4-3 is when the T-junction's $90^{\circ}$ entrance turn angle $2 \mathrm{~m}$ into the entrance location is beveled to $45^{\circ}$; Scenario $4-4$ is when the T-junction's $90^{\circ}$ entrance turn angle $2 \mathrm{~m}$ into the entrance location is beveled to $60^{\circ}$; Scenario 4-5 is when the T-junction's $90^{\circ}$ entrance turn angle $2 \mathrm{~m}$ into the entrance location is beveled to a rounded turn; Scenario 4-6 modifies the width of the T-junction's entrance $(+0.5 \mathrm{~m})$; Scenario 4-7 modifies the width of the T-junction's entrance $(+1.0 \mathrm{~m})$. 


\section{Results and Discussions}

\subsection{Scenario 1}

Table 3 shows the result from Scenario 1, which simulated the exiting process of 400 people at the gate crossing. The result shows that for Scenario 1-1, with five open gates of $50 \mathrm{~cm}$ width each, the time it took for people to disperse is $206 \mathrm{~s}$. After adding two more open gates in Scenario 1-2, the exiting time was reduced to $140 \mathrm{~s}$, which is a reduction of $66 \mathrm{~s}$ and an increase in performance improvement of $31.65 \%$. After adding four more open gates in Scenario 1-3, the exiting time was reduced to $108 \mathrm{~s}$, which is a reduction of $32 \mathrm{~s}$ compared to Scenario 1-2. Scenario 1-4 modified the width of the gates to $70 \mathrm{~cm}$ and increased the number of open gates to five that led to exiting time of $104 \mathrm{~s}$, which reduced the exiting time by almost half as compared to Scenario 1-1, with overall performance increased by almost $50 \%$. When the width of the open gates is at $100 \mathrm{~cm}$ as in Scenario 1-5, the exiting time was reduced by $40 \mathrm{~s}$ as compared to width at $70 \mathrm{~cm}$, which raised performance by $20 \%$. In Scenario 1-6, the width of open gates were increased to $150 \mathrm{~cm}$, the exiting time was $46 \mathrm{~s}$ and overall performance increased by $77 \%$.

\subsection{Scenario 2}

Table 4 presents the simulation results from Scenario 2, which simulated the exiting process of 400 people at the stair locations. The result shows that, for Scenario 2-1 where only one $2.4 \mathrm{~m}$ stair is open, the exiting time is $256 \mathrm{~s}$. After adding one more escalator in Scenario 2-2, the exiting time was about $236 \mathrm{~s}$, a reduction of $20 \mathrm{~s}$ as compared to Scenario 2-1, an improvement of $7.3 \%$. After opening up two more escalators in Scenario 2-2, the exiting time was reduced by almost $1 \mathrm{~min}$, an improvement rate increases of $21 \%$.

\subsection{Scenario 3}

Table 5 displays the result from Scenario 3, which simulated the exiting process of 250 people when encountering turns. The results show that when people in Scenario 3-1 encounter two $90^{\circ}$ turns, the exiting time is $147 \mathrm{~s}$. After the two $90^{\circ}$ turns were modified into $30^{\circ}$ in Scenario 3-2, the exiting time is $131 \mathrm{~s}$, an improvement of $11 \%$. After the two $90^{\circ}$ turns were modified into $45^{\circ}$ in Scenario 3-3, the exiting time was reduced by $2 \mathrm{~s}$ as compared to $30^{\circ}$, an increase in performance of about $2 \%$. After modifying the $90^{\circ}$ turn into a rounded turn as in Scenario 3-5, there was a reduction of $26 \mathrm{~s}$ as compared to before any modification, an increase in performance of $18 \%$.

\subsection{Scenario 4}

Table 6 lists the result from Scenario 4, which simulated the exiting process of 200 people at the $\mathrm{T}$-junction intersection. The result shows that for

Table 3 Simulation results of Scenario 1.

\begin{tabular}{llc}
\hline Scenario & Time (s) & Improvement rate \\
\hline No modification (50 cm and five gates) & 206.0 & - \\
Add Gate 1 (50 cm and seven gates) & 140.8 & $31.65 \%$ \\
Add Gate 2 (50 cm and nine gates) & 108.9 & $47.14 \%$ \\
Modify Width 1 (70 cm and five gates) & 104.5 & $49.27 \%$ \\
Modify Width 2 (100 cm and five gates) & 60.0 & $70.87 \%$ \\
Modify Width 3 (150 cm and five gates) & 46.0 & $77.67 \%$ \\
\hline & & \\
Table 4 Simulation result of Scenario 2. & Time (s) & Improvement rate \\
\hline Scenario & 254.5 & - \\
\hline Regular stair $(2.4$ m) & 235.9 & $7.31 \%$ \\
Regular stair + escalator $\times 1$ & 200.1 & $21.38 \%$ \\
Regular stair + escalator $\times 2$ & & \\
\hline
\end{tabular}


Table 5 Simulation result of Scenario 3.

\begin{tabular}{llc}
\hline Scenario & Time $(\mathrm{s})$ & Improvement rate \\
\hline No modification $\left(90^{\circ}\right)$ & 147.8 & - \\
Modified angle $\left(30^{\circ}\right)$ & 131.7 & $10.89 \%$ \\
Modified angle $\left(45^{\circ}\right)$ & 129.2 & $12.58 \%$ \\
Modified angle $\left(60^{\circ}\right)$ & 128.2 & $13.26 \%$ \\
Modified angle (rounded turn) & 121.2 & $18.00 \%$ \\
\hline
\end{tabular}

Table 6 Simulation result of Scenario 4.

\begin{tabular}{llc}
\hline Scenario & Time $(\mathrm{s})$ & Improvement rate \\
\hline No modification $\left(90^{\circ}\right)$ & 59.1 & - \\
Modified angle $\left(30^{\circ}\right)$ & 58.3 & $1.18 \%$ \\
Modified angle $\left(45^{\circ}\right)$ & 58.9 & $1.02 \%$ \\
Modified angle $\left(60^{\circ}\right)$ & 56.7 & $6.43 \%$ \\
Modified angle (rounded turn) & 58.1 & $1.69 \%$ \\
Modified width $(+0.5 \mathrm{~m})$ & 53.9 & $5.41 \%$ \\
Modified width $(+1.0 \mathrm{~m})$ & 52.7 & $10.83 \%$ \\
\hline
\end{tabular}

Scenario 4-1, which is a normal T-junction intersection with no width and angle modification, the exiting time is $59 \mathrm{~s}$. After the $90^{\circ}$ entrance turn angle was modified to $30^{\circ}$ as in Scenario 4-2, the exiting time reduced to $58 \mathrm{~s}$, a performance rate improvement of $1 \%$. Turn angle modification to $45^{\circ}$ in Scenario 4-3 did not generate any significant change in exiting time. After the turn angle was modified to $60^{\circ}$ as in Scenario 4-4, the exiting time reduced to $55 \mathrm{~s}$, a performance rate improvement of $6.43 \%$. After Scenario 4-5 modified the turn angle to rounded turn, the exiting time reduces to $58 \mathrm{~s}$, a performance reduction of $1 \mathrm{~min}$ as compared to Scenario 4-1. Scenario 4-6 increased the T-junction entrance width by $0.5 \mathrm{~m}$ from the original $3.0 \mathrm{~m}$ to $3.5 \mathrm{~m}$, the exiting time was $53 \mathrm{~s}$, a performance increase of $5.4 \%$ compared to before modification. Scenario 4-7 increased the entrance width to $4.0 \mathrm{~m}$, and the exiting time was $52 \mathrm{~s}$, an increase of 5.4\% compared to Scenario 4-6. For multito single-directional converging T-junction intersections, modification of turn angle increased movement fluency, with higher the modified angle, the higher the increase in fluency. However, while the number of evacuation people is fewer, changing to turn angle or round angle does not have an effect as significant as expected.

\subsection{Brief Summary}

Results of simulations show that, in terms of gate crossing, because the entrance width $(50 \mathrm{~cm})$ and the simulated person's width $(45 \mathrm{~cm})$ did not differ much, most people at the exit location wait for their turn to go through, creating congestion point. Increasing the number of exits increases the chance for people to go through, which can relieve the lines in front of the gate crossings (Fig. 4). By widening the openings, going through crossing gates becomes smoother, so people can more quickly pass through (Fig. 5). Accordingly, the results show that increasing the width of the gates is more beneficial than increase the number of gates. The graphed result is depicted in Fig. 6.

The stair location simulation results show that congestion will occur at the stair entrance as people wait to get on the stairs (Fig. 7). So how to effectively redirect crowds waiting in front of the stairs is the plan for improvement. When the right staircase opens, people can use the staircase on the right to make their exit (Fig. 8). When both staircases open, people can use all three staircases to make their exit, which greatly ease the waiting crowd in front of the stairs. Therefore, as people make their exit in one direction, so long as all the stairs can be set as unidirectional, the overall 


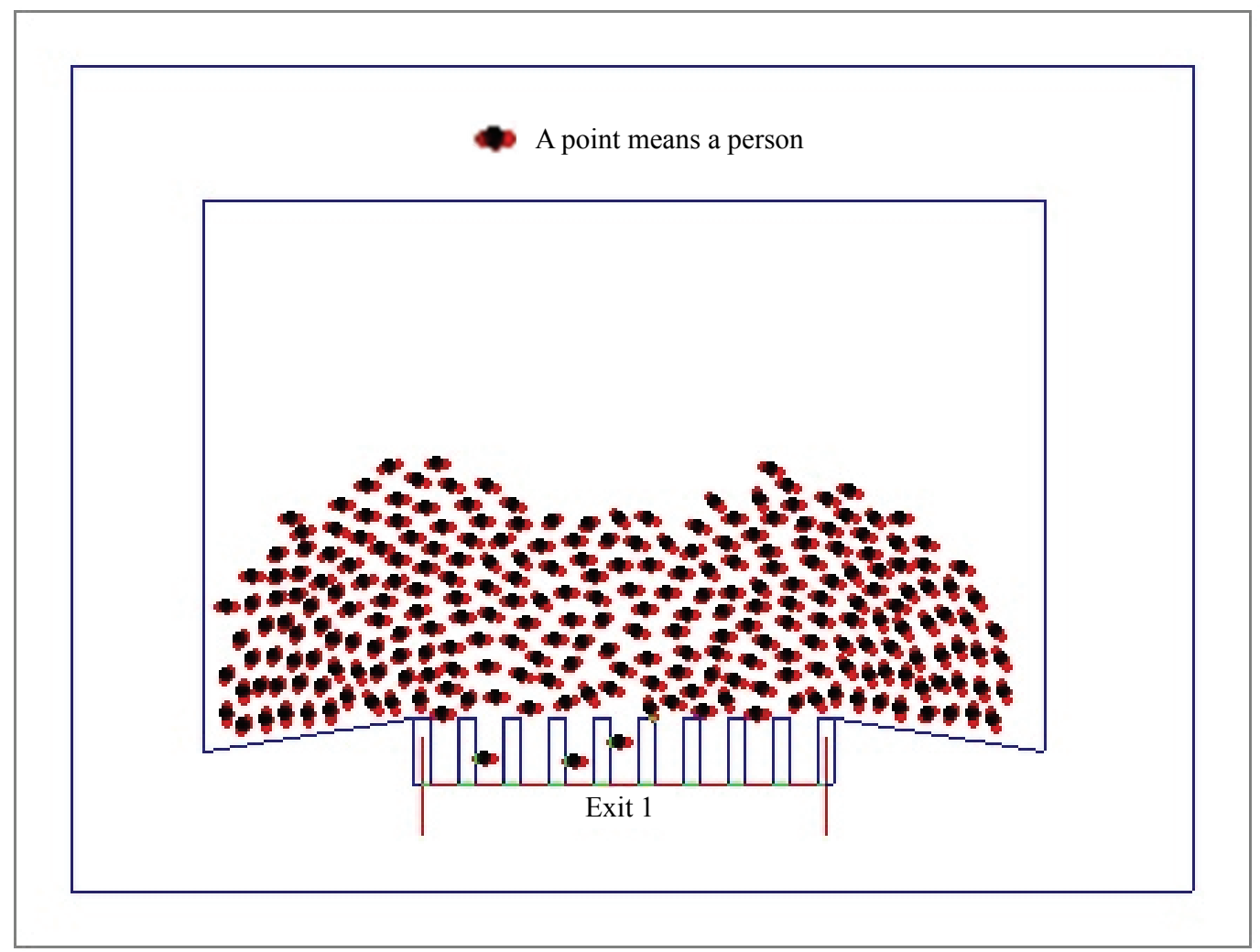

Fig. 4 Simulation diagram of adding more exits.

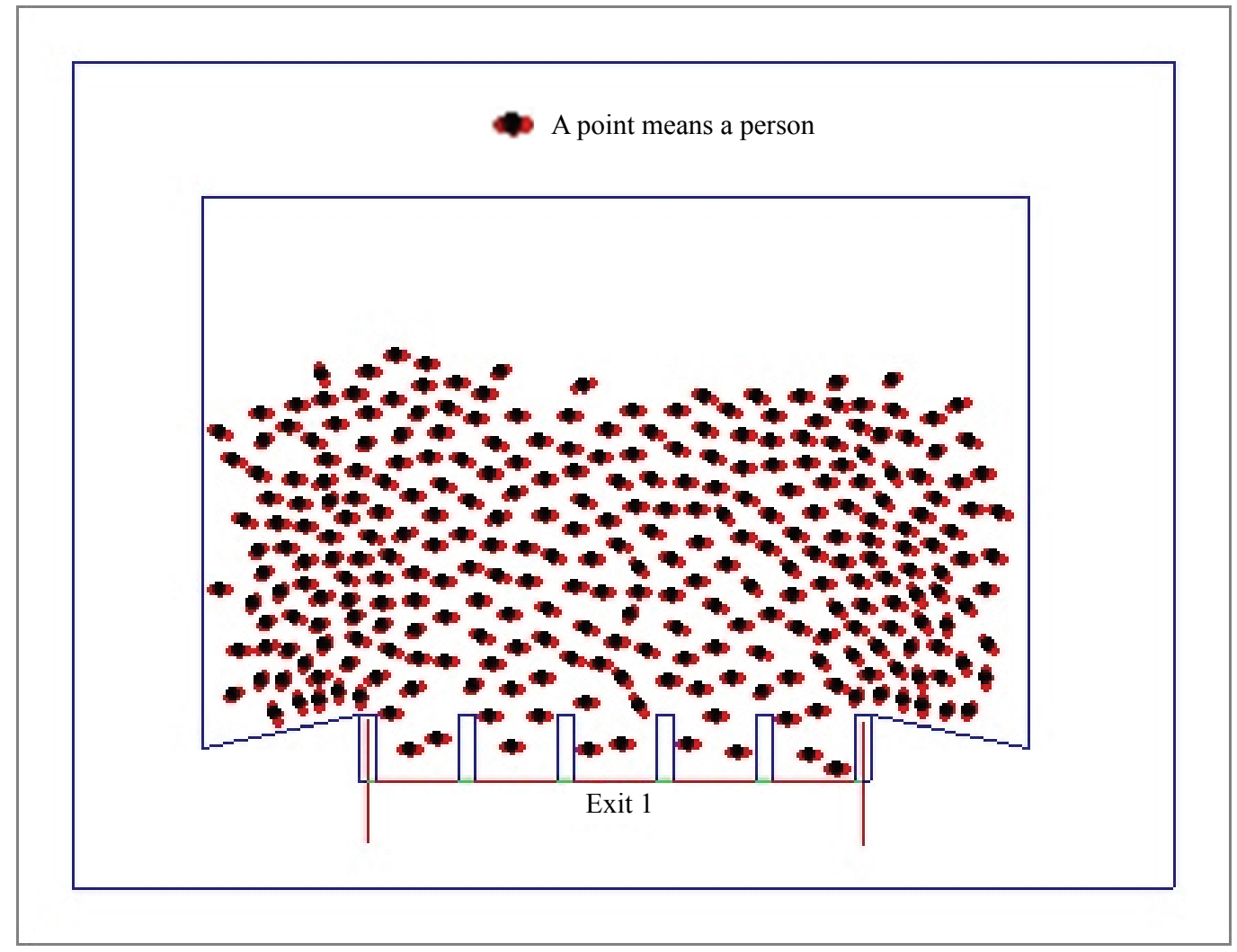

Fig. 5 Situational diagram of increasing gate width. 


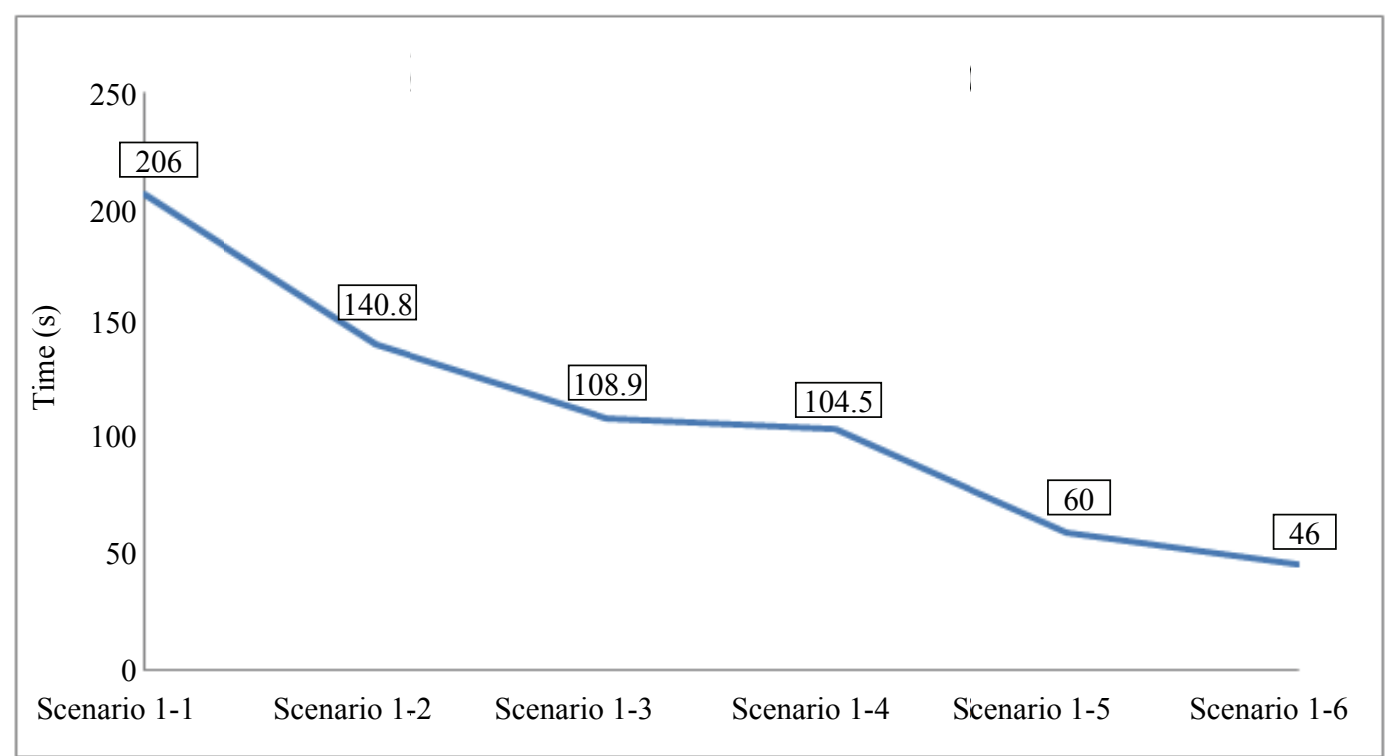

Fig. 6 Graphed result of gate crossing simulation in Scenario 1.

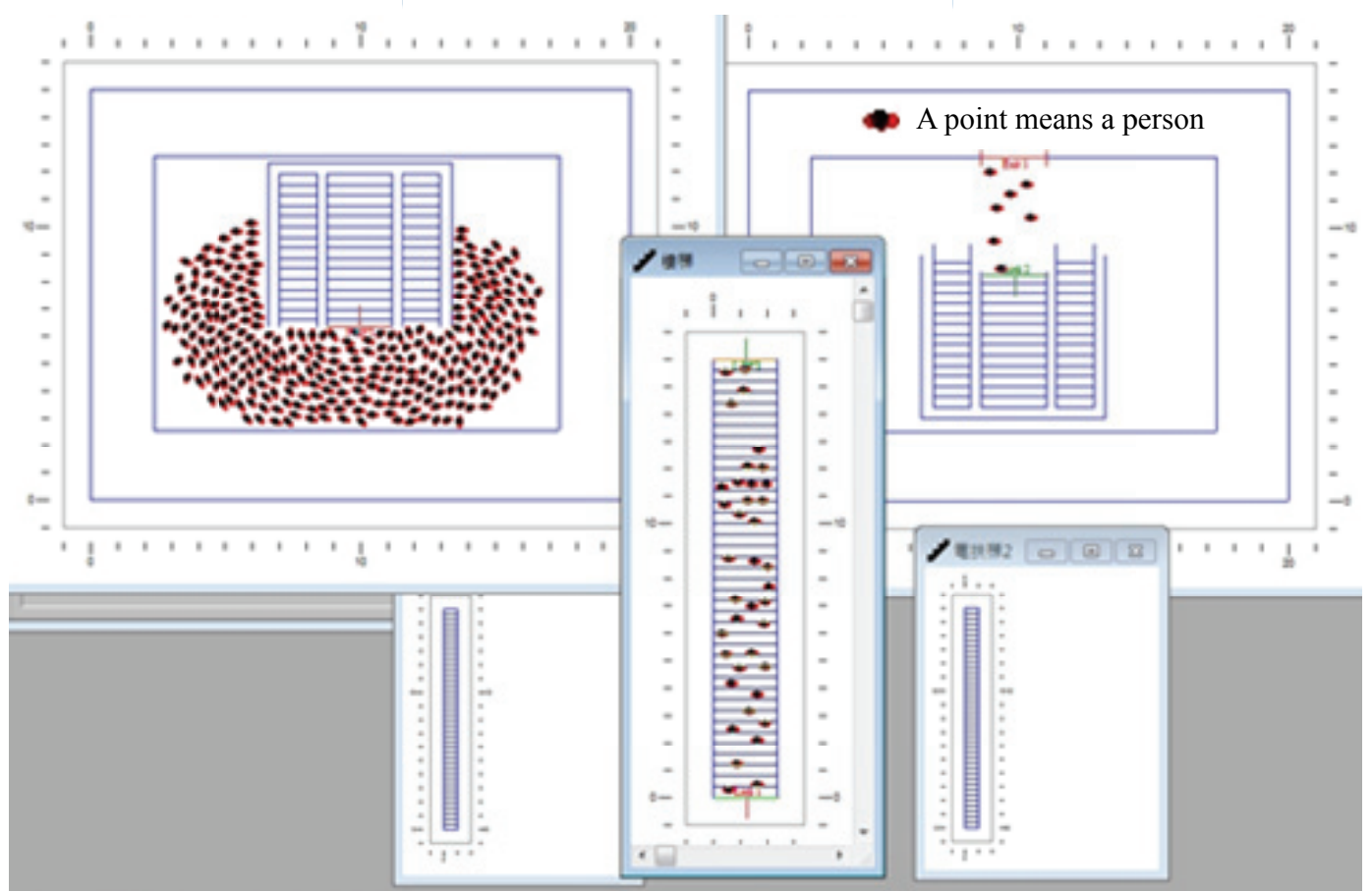

Fig. 7 Situational diagram of congestion in front of stairs.

exiting time could be greatly improved. The graphed result is delineated in Fig. 9.

Three-turn simulation in Scenario 3 shows that the speed of people moving through two $90^{\circ}$ turns tends to reduce as a result of significant turn because of right angle relationship, which causes congestion point to occur (Fig. 10). Modification of the turn angle increases fluency of movement, and greater the turn angle modification, the higher the fluency (Fig. 11). Therefore, in terms of turn locations, replacing right angles or other more moderate angles with circular arc can make the overall moving line along the exiting process smoother. The graphed result is shown in Fig. 12.

The simulation result of multi- to single-direction convergence at T-junction intersection in Scenario 4 


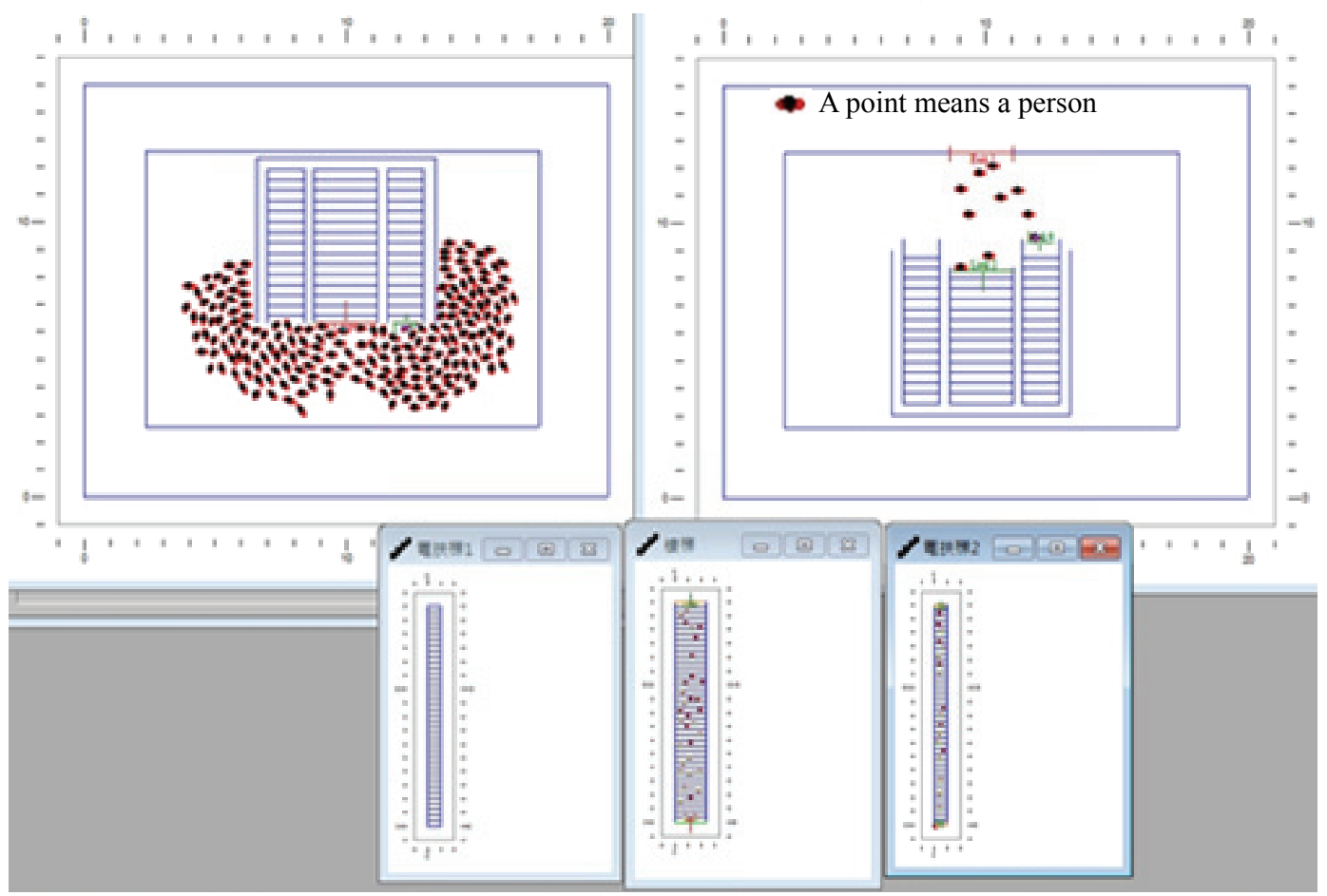

Fig. 8 Situational diagram of opening one escalator.

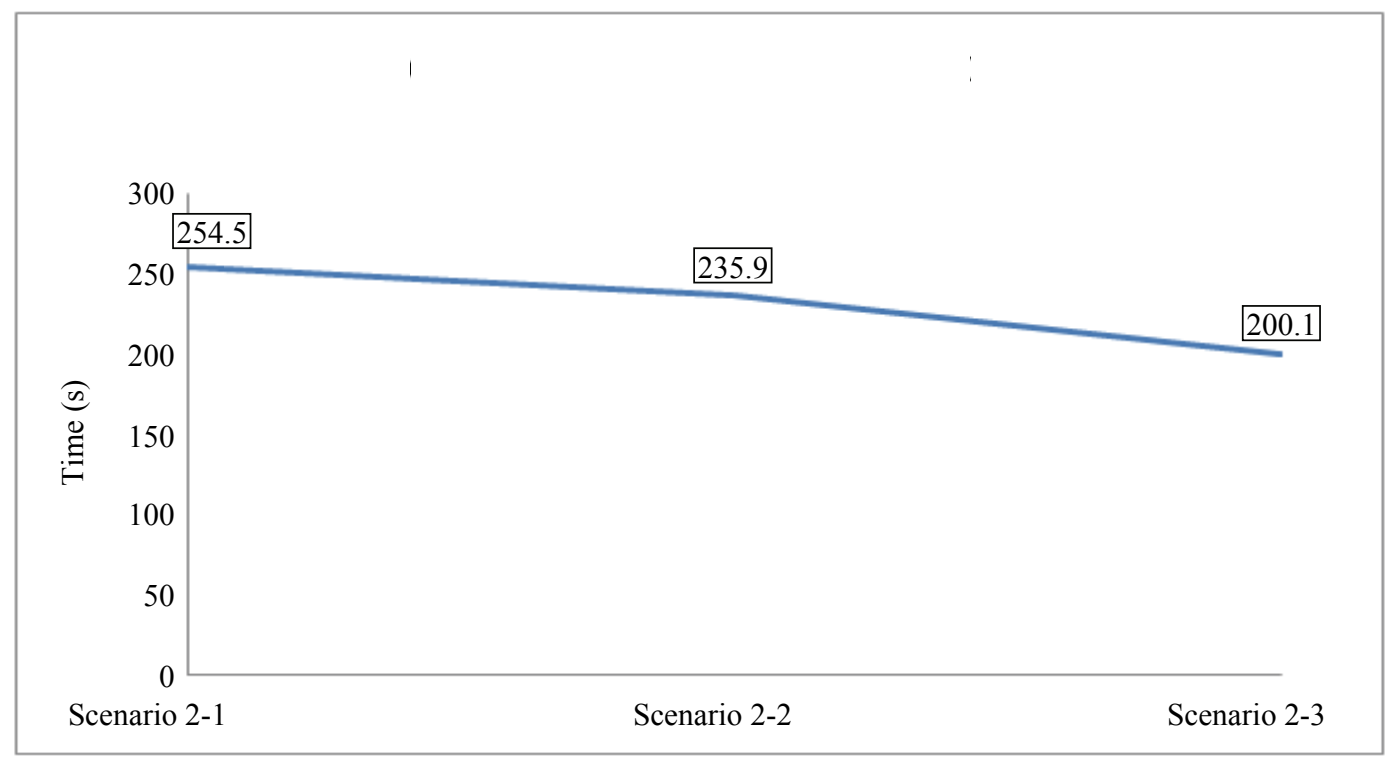

Fig. 9 Graphed result of stair location simulation in Scenario 2.

shows that the situation of people approaching a turn location is similar to a right angle relationship in which the speed of people moving around a significant turn is reduced, resulting in the generation of a congestion point (Fig. 13). Modification of turn angle raises the fluency of movement, with greater the angle, the higher the fluency (Fig. 14). However, improvements from round angle modification were not as significant as expected. The width of gate opening needs to be increased to $1.0 \mathrm{~m}$ before any significant improvements will occur. Therefore, overall comparison shows that improvements from turn angle modification to $60^{\circ}$ is more effective. The graphed result is shown in Fig. 15. 


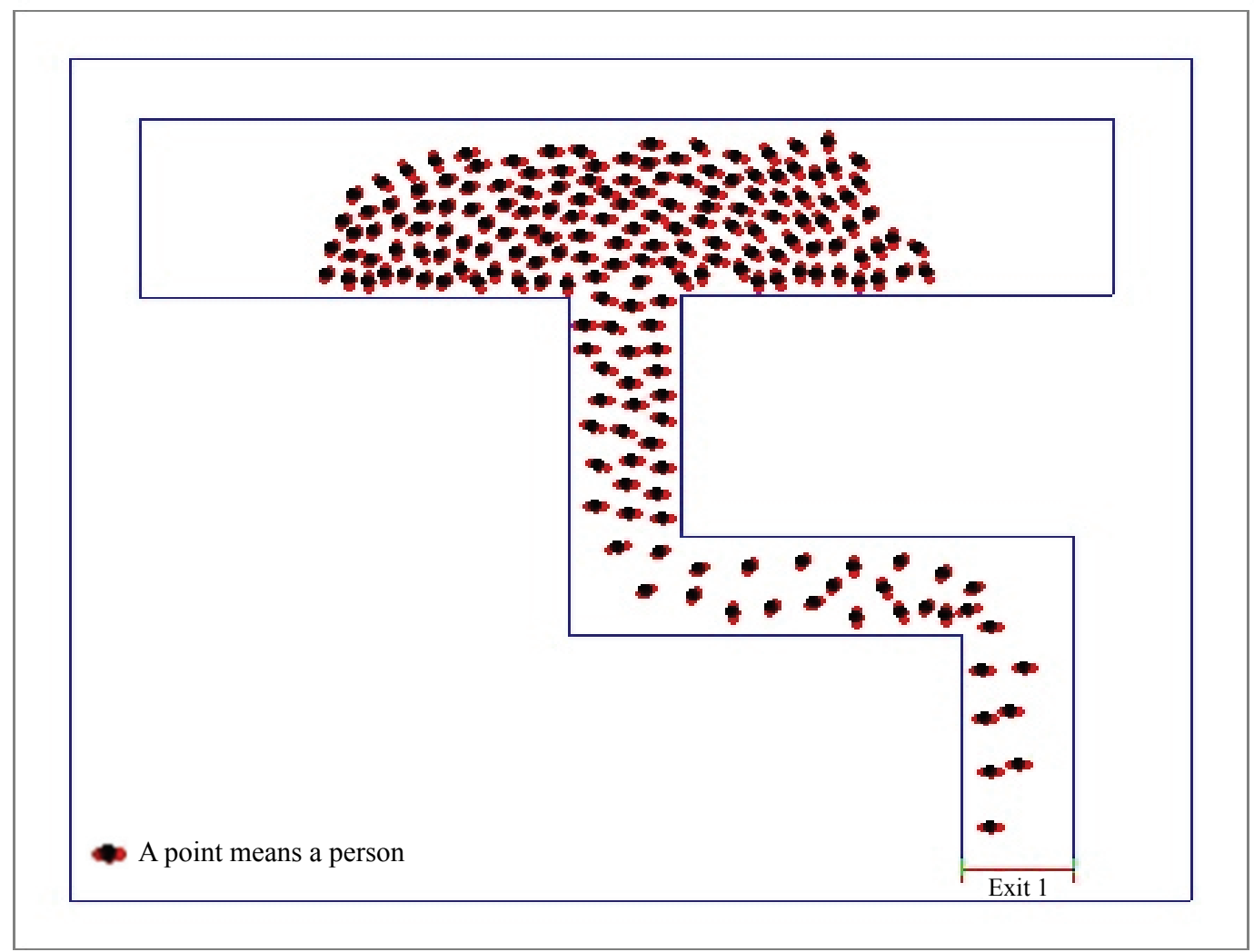

Fig. 10 Situational diagram of congestion at turns.

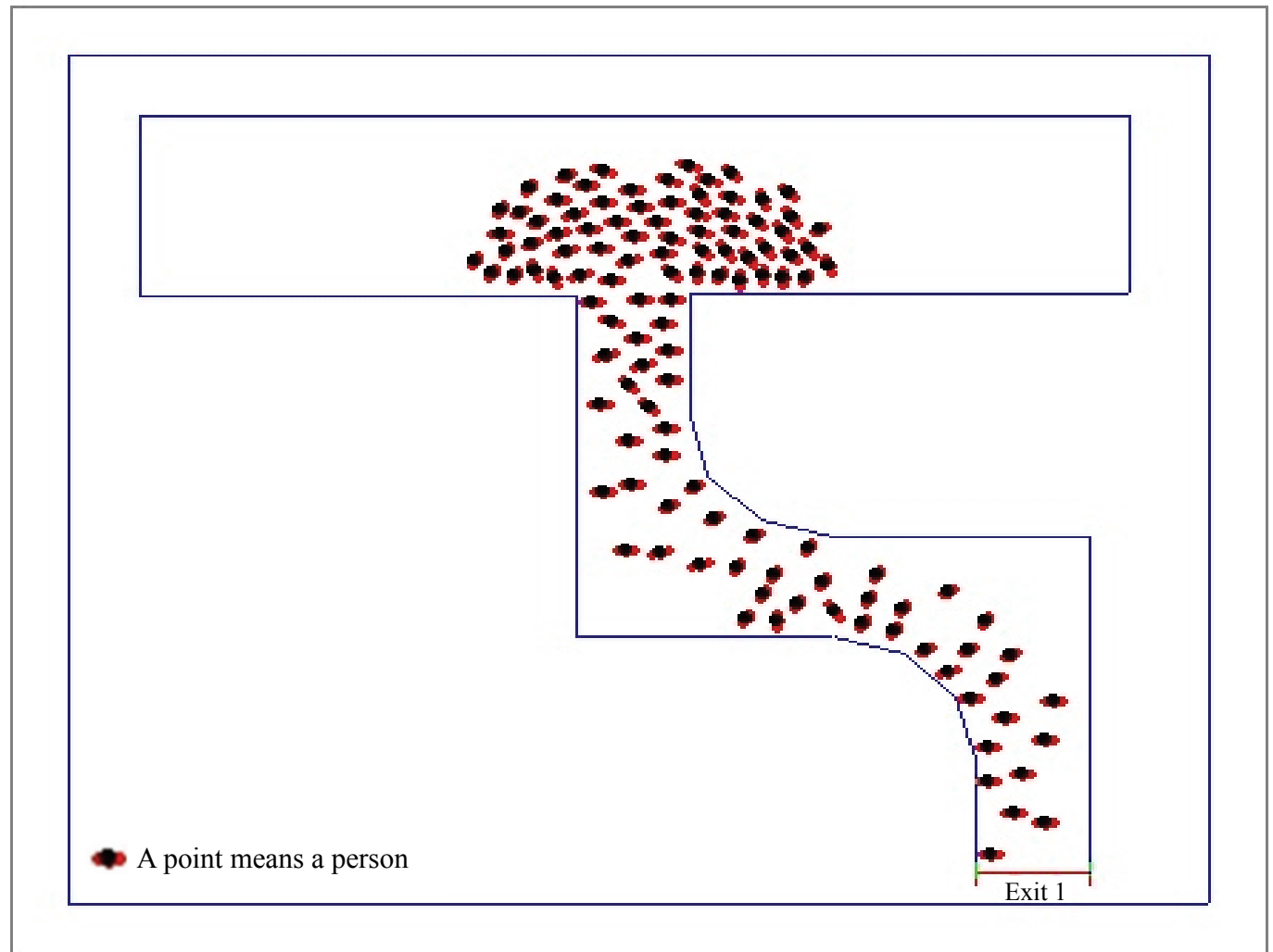

Fig. 11 Situational diagram of traffic fluency after round corner modification. 


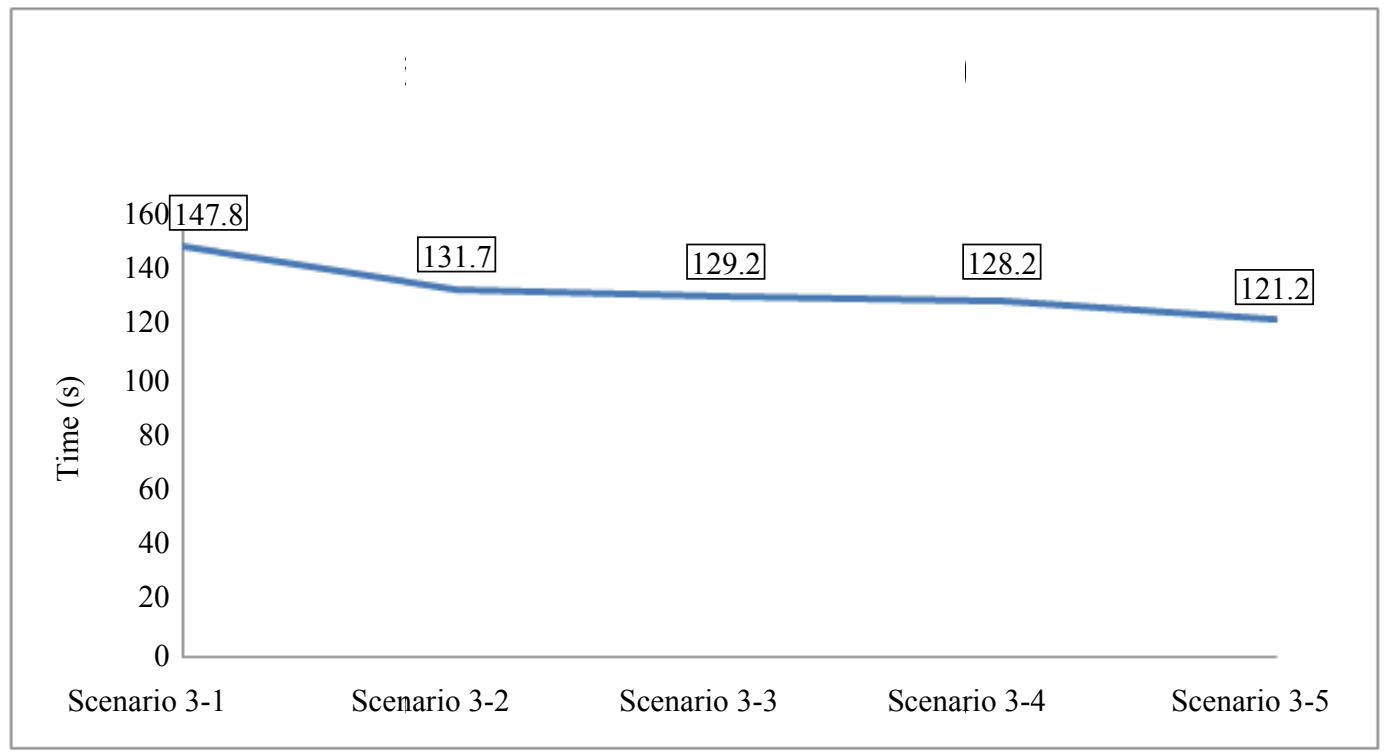

Fig. 12 Graphed result of turn location simulation in Scenario 3.

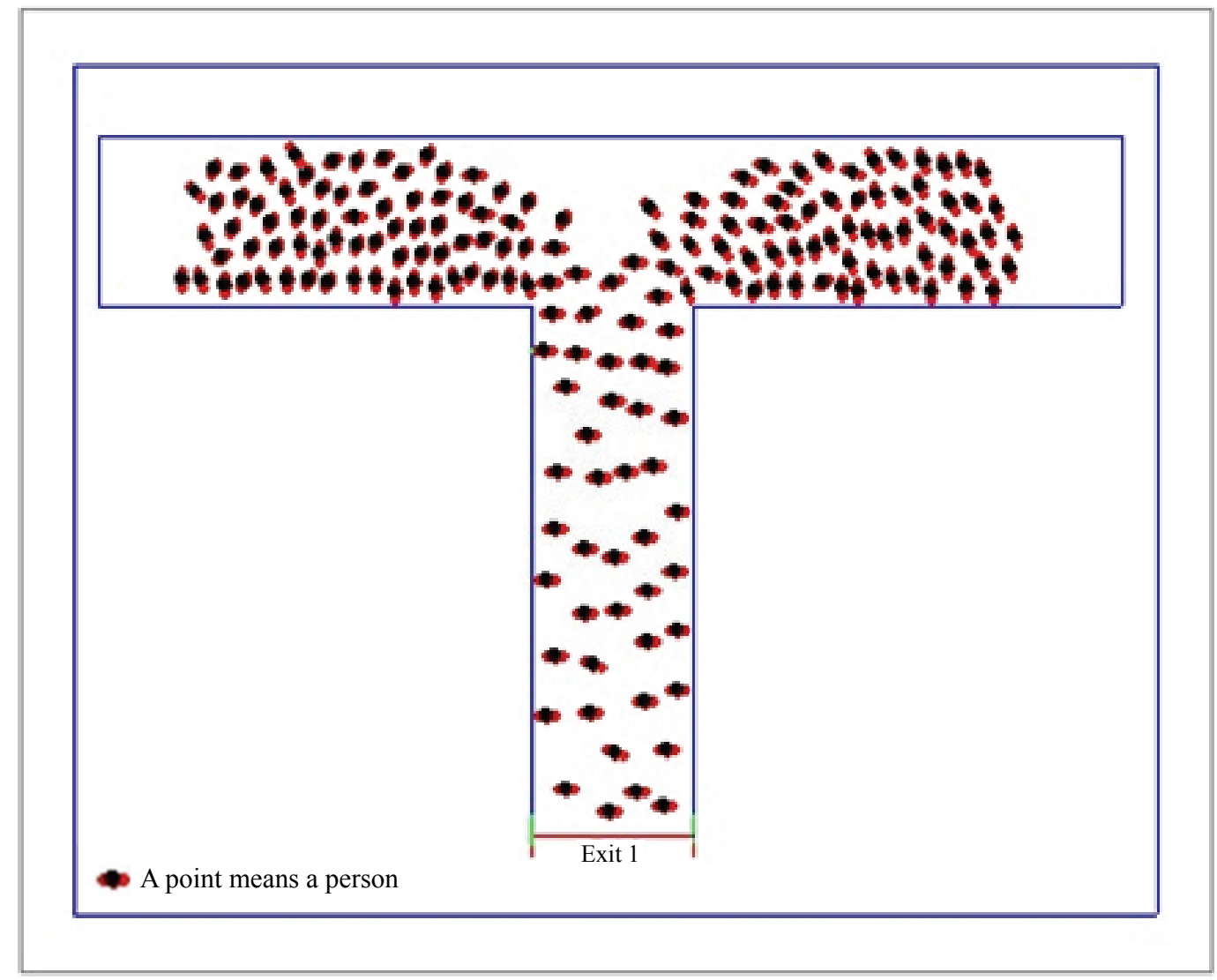

Fig. 13 Situational diagram of congestion at T-junction intersection. 
A point means a person

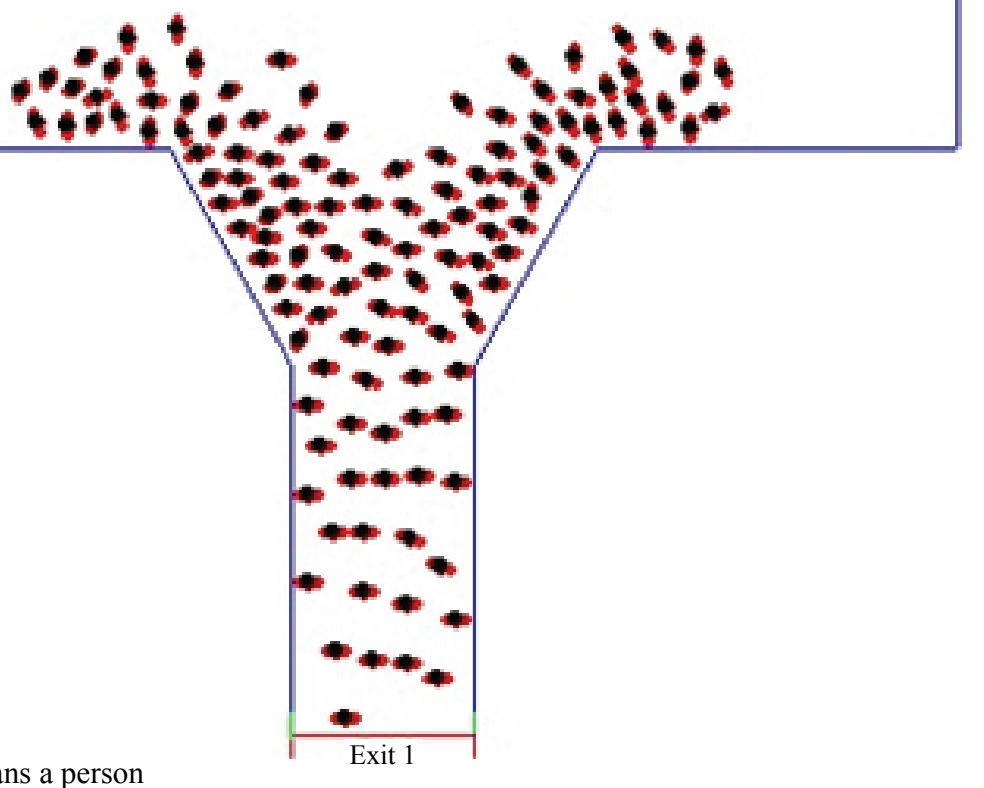

Fig. 14 Situational diagram of exiting process after turn angle modification.

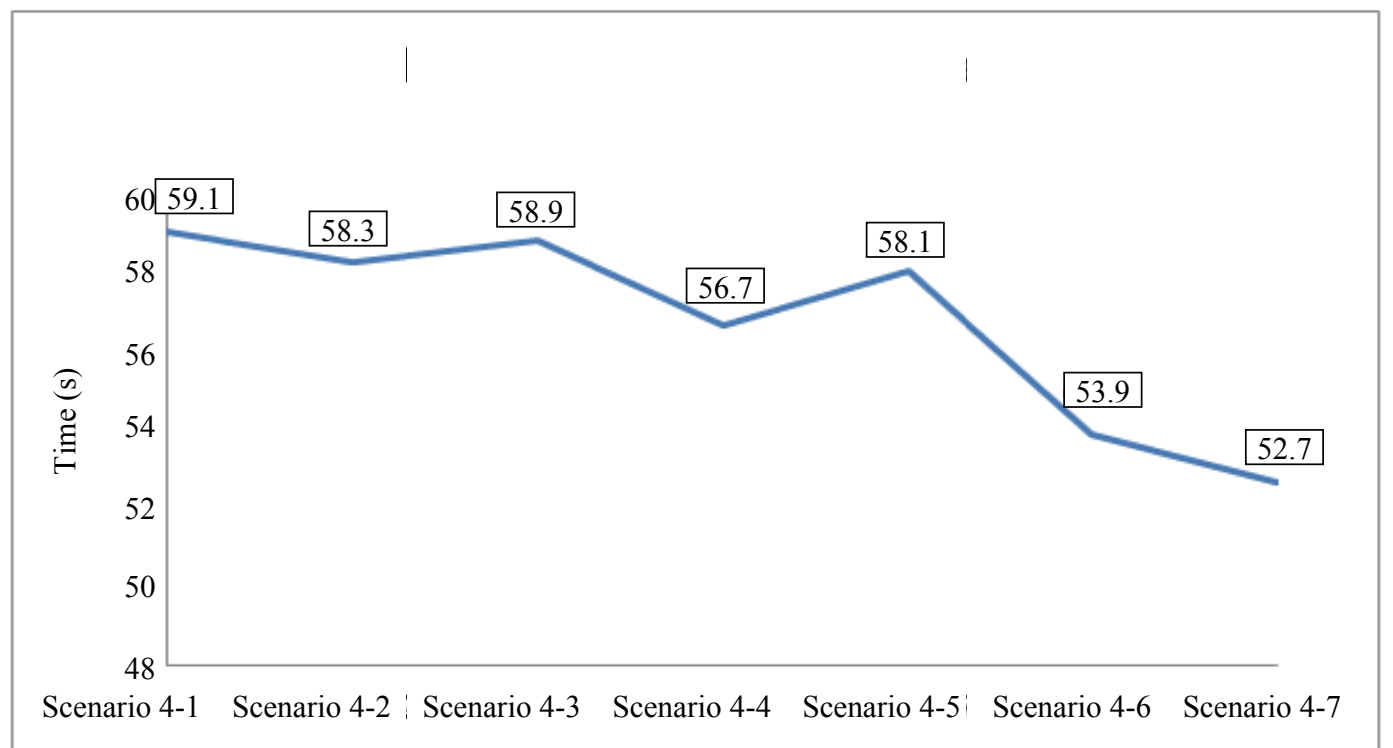

Fig. 15 Graphed result of T-junction intersection simulation in Scenario 4.

\section{Conclusions}

The study focuses on the amount of time it takes to exit a big dome by using computer-assisted dynamic exit simulation software to obtain a simulated sports stadium exiting process with results that match with real world situation, which is used to explore how people use the safest, smoothest, and shortest time to complete their exit. The results and discoveries obtained in the study can be summarized as follows: 
- Simulation analysis of congestion points shows that increasing the width of gate opening can increase the number of people passing through single opening gates. Therefore, for gate crossings, increasing the width of gate openings is more effective than increasing the number of gates;

- For stairs, due to the limited number of stairs and their width, when people are exiting in a single direction, as long as the stairs are also set to a single direction, the overall exit time can be greatly improved;

- For turn locations, it was found that fixing the plane angle did not significantly raise the overall exiting efficiency. But replacing the right angle or other angles with arc angle makes overall exiting moving line more fluent;

- For multi- to single-directional converging T-junction intersections, modification of turn angle increased the movement fluency, with higher the modified angle, the higher the increase in fluency. However, changing to round angle does not have as a substantial effect as expected while gate opening width must be increased to $1.0 \mathrm{~m}$ before more significant effects are produced. Therefore, overall, modifying turn angles to $60^{\circ}$ produces better improvements;

- Simulation using Simulex revealed that people choosing the nearest moving line when exiting is the key to the whole exiting behaviors. Recording of how people choose moving lines and obstacles along the moving process during simulation allows simulation results to further reflect actual situation.

\section{Acknowledgments}

The authors are indebted to Ministry of Science and Technology of Taiwan, Republic of China, for the financial support.

\section{References}

[1] Chow, W. K., and Li, J. 2000. "Possibility of Using a Time Constant in Fire Codes for Smoke Management in Atria." Journal of Fire Sciences 18 (2): 130-50.

[2] BSI (British Standards Institute). 1999. Part 0-11, BS 5588 Fire Precautions in the Design, Construction and Use of Buildings. London: BSI.
[3] Thompson, P. A., and Marchant, E. W. 1995. "A Computer Model for the Evacuation of Large Building Populations." Fire Safety Journal 24: 131-48.

[4] Fang, Z., Wang, P., Chen, D., Chen, D. H., Duan, J. X., and $\mathrm{Hu}, \mathrm{Z}$. R. 2004. "The Development of Evaluation Software of Safety Evacuation for High Buildings." Fire Science and Technology 23 (5): 439-42.

[5] Kady, R. A., and Davis, J. 2009. "The Effect of Occupant Characteristics on Crawling Speed in Evacuation." Fire Safety Journal 44: 451-7.

[6] Lee, D., Kim, H., Park, J. H., and Park, B. J. 2003. "The Current Status and Future Issue in Human Evacuation from Ships." Safety Science 41: 861-76.

[7] Gwynne, S., and Galea, E. R. 1997. A Review of Methodologies and Critical Appraisal of Computer Models Used in the Simulation of Evacuation from the Built Environment. Gaithersburg: Society of Fire Protection Engineers.

[8] Ozel, F. 1992. "Simulation Modeling of Human Behaviour in Buildings Simulation." Simulation 58 (6): 377-84.

[9] Fahy, R. F. 1991. "An Evacuation Model for High Rise Buildings." In Proceedings of the Third International Symposium on Fire Safety Science, 815-23.

[10] Levin, B. 1989. "EXITT-A Simulation Model of Occupant Decisions and Actions in Residential Fires." In Proceedings of the Second International Symposium on Fire Safety Science 1989, 561-70.

[11] Ketchelln, N., Cole, S. S., Webber, D. M., Marriott, C. A., Stephens, P. J., Brearley, I. R., et al. 1993. "The EGRESS Code for Human Movement and Behaviour in Emergency Evacuation.” In Engineering for Crowd Safety, edited by Smith, R. A., and Dickie, J. F. Edinburgh: University of Edinburgh, 361-70.

[12] Thompson, P., and Marchant, E. A. 1995. "Computer Model for the Evacuation of Large Building Populations." Fire Safety Journal 24: 131-48.

[13] Owen, M., Galea, E. R., and Lawrence, P. J. 1996. "The Exodus Evacuation Model Applied to Building Evacuation Scenarios." Journal of Fire Protection Engineering 8 (2): 655-86.

[14] Galea, E. R., and Galparsoro, J. M. P. 1994. "Exodus: An Evacuation Model for Mass Transport Vehicles." Fire Safety Journal 22: 341-66.

[15] Proulx, G. 1999. "Occupant Response during a Residential Highrise Fire." Fire and Materials 23: 317-23.

[16] Shields, T. J., and Boyce, K. E. 2000. "A Study of Evacuation from Large Retail Stores." Fire Safety Journal 35: 25-49.

[17] Zhang, J., Song, W., and Xu, X. 2008. "Experiment and Multi-grid Modeling of Evacuation from a Classroom." 
Physica A 387: 5501-9.

[18] Chow, W. K., Candy, M., and Ng, Y. 2008. "Waiting Time in Emergency Evacuation of Crowded Public Transport Terminals.” Safety Science 46: 3757-61.

[19] Nilsson, D., and Johansson, A. 2008. "Social Influence during the Initial Phase of a Fire Evacuation-Analysis of Evacuation Experiments in Cinema Theatre.” Fire Safety Journal 44 (1): 71-9.

[20] Hoogendoorn, S. P., and Daamen, W. 2005. "Pedestrian Behavior at Bottlenecks.” Transportation Science 39 (2): 147-59.

[21] Hoogendoorn, S. P., and Bovy, P. H. L. 2003. "Simulation of Pedestrian Flows by Optimal Control and
Differential Games.” Optimal Control Applications \& Methods 24 (3): 153-72.

[22] Kretz, T., Grunebohm, A., Kaufman, M., Mazur, F., and Schreckenberg, M. 2006. "Experimental Study of Pedestrian Counterflow in a Corridor." Journal of Statistical Mechanics-Theory and Experiment 10: P10001-14.

[23] Integrated Environmental Solution Ltd. 2013. SIMULEX User Guide, Virtual Environment 6.0. Glasgow: Integrated Environmental Solution Ltd.

[24] Kiwa, H. 2003. Architectural Planning and Design Series 27 Music Hall Theater, Cinema. Ichigaya: Ichigaya Publisher, 151-3. 